\title{
A NOTE ON THE K-DOMINATION NUMBER OF A GRAPH
}

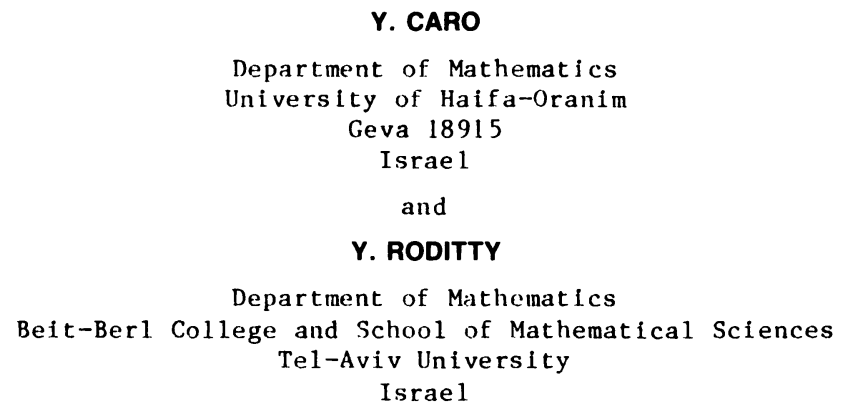

(Received December 30, 1988 and In revised form February 1, 1989)

\begin{abstract}
The k-domination number of a graph $G=G(V, E), \gamma_{k}(G)$, is the least cardinality of a set $X \subset V$ such that any vertex in $V X$ is adjacent to at least $k$ vertices of $X$.

Extending a result of Cockayne, Gamble and Shepherd [4], we prove that if $\delta(G)>\frac{n+1}{n} k-1, n>1, k \geqslant 1$ then, $r_{k}(G)<\frac{n p}{n+1}$, where $p$ is the order of $G$.
\end{abstract}

KEY WORDS AND PHRASES. k-dominating set and k-domination Number. 1980 AMS SUBJECT CLASSIFICATION CODE. 05C35.

1. INTRODUCTION.

A set $X$ of vertices of a graph $G=G(V, E)$ is $k$-dominating if each vertex of $V \backslash X$ is adjacent to at least $k$ vertices of $X$. The $k$-domination number of a graph $G$, $\gamma_{k}(G)$, is the smallest cardinality of a k-dominating set of $G$.

We write $\delta=\delta(G)$ for the minimum degree of vertices in $G$ and $|G|=p$ is the number of vertices of $G$.

Several results concerning $y_{k}(G)$ have been established by Fink and Jacobson [1],

[2] who showed that $Y_{k}>\frac{k p}{\Delta+k}$, and recently by Favaron [3].

As for the upper bound, Cockayne, Gamble and Shepherd proved the following:

THEOREM 1.1. If $G$ has $p$ vertices and $\delta>k$, then $\gamma_{k}(G)<\frac{k p}{k+1}$.

2. MAIN RESULTS.

Our aim in this note is to extend Theorem 1.1 and give a shorter proof of that given in Cockayne, Gamble, and Shepherd [4]. We prove, 
THEOREM 2.1. Let $\mathrm{n}, \mathrm{k}$ be positive integers and $\mathrm{G}$ a graph such that $\delta(G)>\frac{n+1}{n} k-1$. Then, $\gamma_{k}(G)<\frac{n p}{n+1}$.

PROOF. Let $v_{1}, v_{2}, \ldots, v_{n+1}$ be a partition of $V(G)$ into $n+1$ subsets which maximizes the number of edges in $E^{\prime}$ where $E^{\prime}=E(G) \backslash_{i=1}^{n+1} E\left(\left\langle V_{i}\right\rangle\right)$ and $\left\langle V_{i}\right\rangle$ is the subgraph induced on the vertex set $v_{i}$.

By a classical argument of Erdös [5] we have that for every $x \in V$, $\operatorname{deg}_{H}(x)>$ $\left[\frac{n}{n+1} \operatorname{deg}_{G}(x)\right]$, where $H=H\left(V^{\prime}, E^{\prime}\right), V^{\prime}=V$, and $E^{\prime}$ is as above. Hence we conclude that:

$$
\operatorname{deg}_{H}(x)>\left[\frac{n}{n+1}\left(\frac{n+1}{n} k-1\right)\right]=\left[k-\frac{n}{n+1}\right]=k
$$

Assume w.L.0.G. that $\left|v_{1}\right| \geqslant\left|v_{2}\right| \geqslant \ldots>\left|v_{n+1}\right|$. Then the set $A=\underset{i=2}{u+1} v_{i}$ is a kdominating set of $G$ since each vertex $x \in V_{1}$ is adjacent to at least $k$ vertices of A. Thus it follows that $\gamma_{k}(G)<p-\left|v_{1}\right|<\frac{n p}{n+1}$.

COROLLARY 1. [4] If $\delta(G)>k$ then $\gamma_{k}(G)<\frac{k p}{k+1}$.

PROOF. Take $\mathrm{n}=\mathrm{k}$ in Theorem 2.1.

COROLLARY 2: If $\delta(G)>2 k-1$ then $\gamma_{k}(G)<\frac{p}{2}$.

REMARK. Using a similar argument we can prove the following:

$$
\text { If } \delta(G)>k>1 \text { and } x(G)=n \text {, then } \gamma_{k}(G)<\frac{(n-1) P}{n} \text {. }
$$

REFERENCES

1. FINK, J.F. and JACOBSON, M.S., n-Domination in Graphs, Graph Theory with Applications to Algorithms and Computer Science, Proc. of 5th international Conference, Kalamazoo (1984), 283-300.

2. FINK, J.F. and JACOBSON, M.S., On n-Domination, n-Dependence and Forbidden Subgroups, id. 301-311.

3. FAVARON, 0., k-Domination and k-Independence in Graphs, Technical report Orsay, France (1987).

4. COCKAYNE, E.J., GAMBLE, B., SHEPHERD, B., An Upper Bound for the k-Domination Number of a Graph. J. of Graph Theory 9 (1985), 533-534.

5. ERDOS, P., On some Extrema1 Problems in Graph Theory, Israel J. of Mathamatics 3(1965), 113-116. 


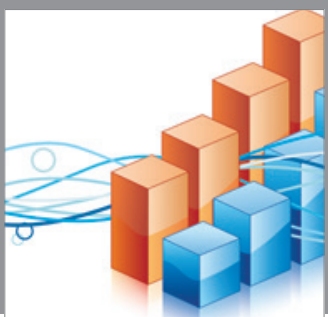

Advances in

Operations Research

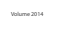

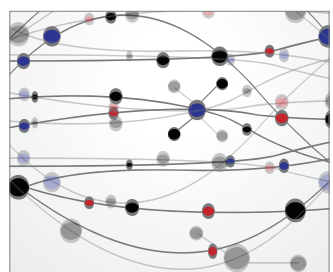

\section{The Scientific} World Journal
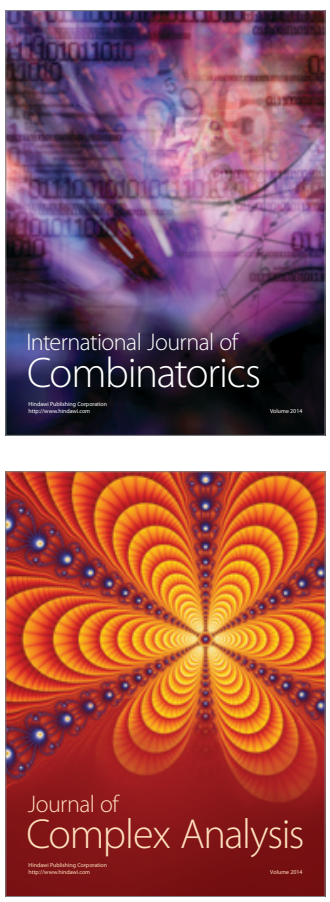

International Journal of

Mathematics and

Mathematical

Sciences
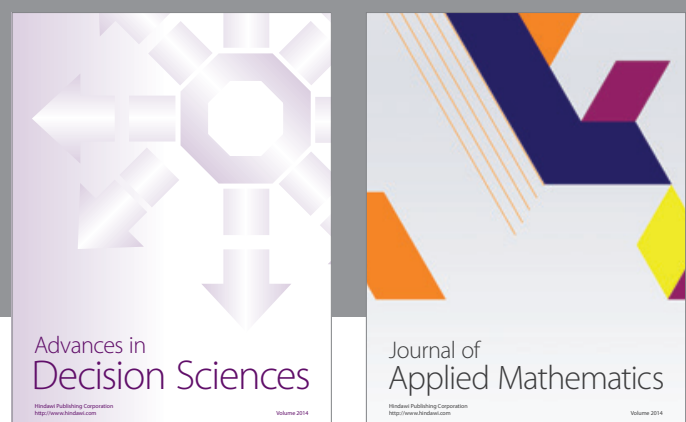

Journal of

Applied Mathematics
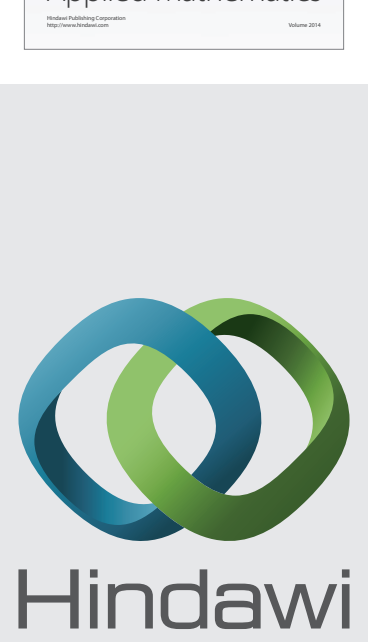

Submit your manuscripts at http://www.hindawi.com
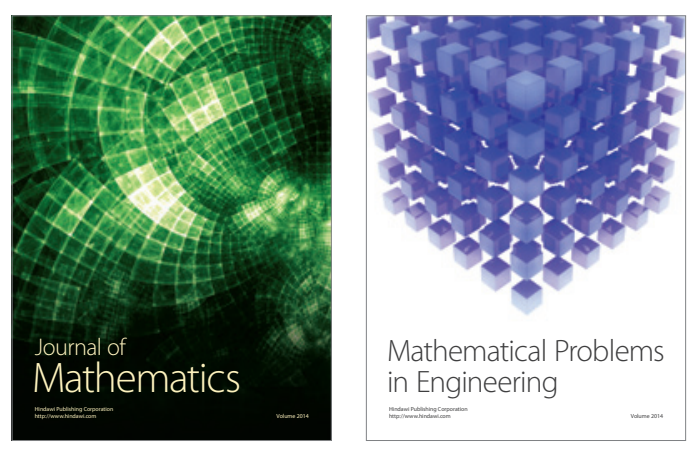

Mathematical Problems in Engineering
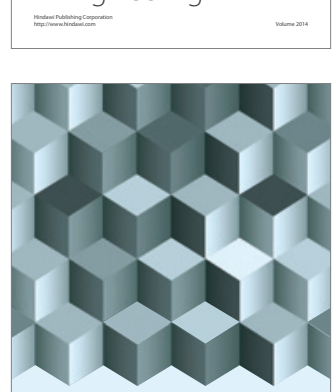

Journal of

Function Spaces
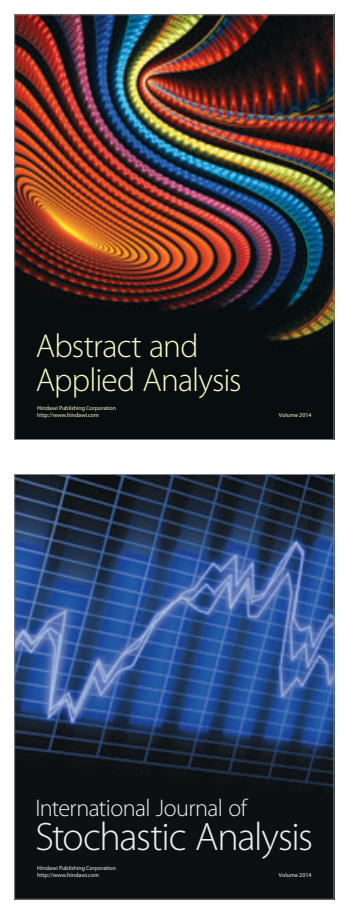

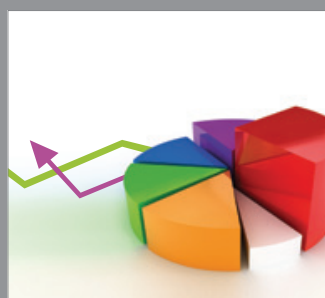

ournal of

Probability and Statistics

Promensencen
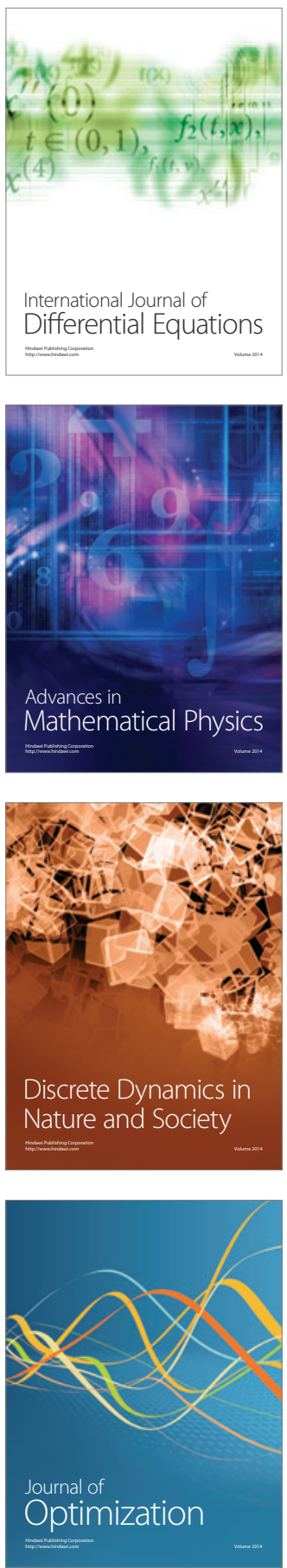